\title{
Life Quality Assessment in Patients with Type 1 Spinocerebellar Ataxia in the Yakut Population
}

\author{
A.A. Maksimova ${ }^{1, *}$, A.I. Fedorov ${ }^{1}$, A.L Sukhomyasova ${ }^{1,2}$ and N.R. Maksimova ${ }^{1}$ \\ ${ }^{1}$ M.K. Ammosov North-Eastern Federal University, Yakutsk, Russia \\ ${ }^{2}$ State Autonomous Institution of the Republic of Sakha (Yakutia) Republic Hospital No. 1 National Center of \\ Medicine, Yakutsk, Russia \\ ${ }^{*}$ Corresponding author. Email: aa.maksimova@ $s$-vfu.ru
}

\begin{abstract}
Parameters of life quality in 12 patients with type 1 spinocerebellar ataxia (SCA1) in the Yakut population were studied. The control group was 12 healthy individuals. A SF-36 questionnaire was used to determine life quality, reflecting overall well-being and satisfaction degree with the physical and psychological components of health According to the research results, a decrease in the life quality occurs for most indicators of hereditary neurological pathology. This is evidenced by statistically significant differences in their averages compared to healthy individuals. A life quality feature of Yakut SCA1 patients can be considered a relatively good preservation of mental health. Patients also maintain vital activity, normal level of communication and social contacts that are quite comparable to those of healthy persons.
\end{abstract}

Keywords: life quality, type 1 spinocerebellar ataxia, SCA1, Yakutia

\section{INTRODUCTION}

Spinocerebellar ataxias (SCAs) are one of the inherited progressive neurodegenerative disorders and belong to the phenotypically and genetically diverse group of cerebellar ataxias. Many of the SCAs have an autosomal dominant inheritance pattern. The prevalence of SCAs is known as $1-5$ cases per 100,000 persons [1].

Each SCA have different clinical manifestations, and mutations in more than 30 distinct genetic loci encoding protein kinases, protein phosphatases, membrane receptors, intracellular ion channels, plasma membrane, and protein with unknown function [2].

Approximately $80 \%$ of autosomal dominant SCA cases are one of SCA 1, 2, 3, 6, and 7, which are the most common polyQ expansion disorders [3, 4].

Spinocerebellar ataxia type 1 (SCA1) (OMIM 164400) refers to polyglutamine diseases characterized by a dynamic mutation - expansion of trinucleotide repeats of cytosine-adenine-guanine (CAG) in the coding regions of the corresponding genes $[5,6]$. Clinical manifestations of type 1 spinocerebellar ataxia
(SCA1) are characterized by the development of cerebellar-pyramid syndrome, its rapid progression, leading to social dysadaptation of patients, to a significant decrease in their life expectancy [7].

Typical SCA1 presents during the third or fourth decades (ranging from 7 to 50 years) with symmetric gait abnormality and progressive ataxia related to cerebellar dysfunction. Many patients are wheelchairbound by the age of 15-20 years. Pathologic findings are associated with atrophy in Purkinje cells of not only the cerebellum but also the pons and middle cerebellar peduncle. SCA1 is characterized by extracerebellar features and corticospinal tract dysfunctions such as hyperreflexia and spasticity in more than $50 \%$ of patients $[8,9]$.

Life quality is one of the main indicators of wellbeing for patients with SCA1 that cannot be cured.

Life quality (LQ) (by WHO definition) is a characteristic of physical, psychological, emotional and social functioning, based on its subjective perception. 
The life quality study is becoming an urgent and integral problem in the management of patients with various diseases. LQ is an assessment of the effect of the disease and treatment on its physical, psychological, emotional and social functioning. It is associated with the clinical endpoints, which makes this indicator very important in clinical studies [10]. The SF-36 questionnaire (Medical Outcomes Study Short-Form 36) is the most common standardized tool for studying LQ in a population, allowing to evaluate different components of patient's life.

Due to extensive use and experience across patients and general population, the generic SF-36 questionnaire also allows to compare patient perceived health status across a variety of disorders and with the general population [11].

The aim of the present research was to assess the life quality of patients with SCA type 1 in the Yakut population.

\section{MATERIALS AND METHODS}

The study included 12 patients diagnosed with SCA1 who were admitted to the Medical and Genetic Center (MGC) of the "Republic Hospital No. 1 National Center of Medicine" between March and May 2021. The control group was 12 healthy people. The assessment of the life quality of patients with SCA1 and a healthy population was carried out with non-specific questionnaire SF-36 (SF-36 Health Status Survey), adapted by the Institute of Clinical and Pharmacological Research, St. Petersburg.

The results of the survey were standardized for the US general population. Primary data processing was carried out according to instructions developed by Evidence Clinical and Pharmacological Research.

The questionnaire contains 36 questions aimed at identifying the life quality of respondents according to 8 scales: physical functioning, role-playing activities, body pain, general health, vitality, social functioning, emotional state and mental health (Tab. 1). A score of results is used, where large values correspond to a high level of life quality. In turn, scales form physical and psychological components of health (Fig. 1).

Table 1. Content of the SF-36 Health Survey.

Label SF-36 QUESTIONS

$\mathrm{GH} 1$ 1. In general, would you say your health is:

HT 2. Compared to one year ago, how would you rate your health in general now?

3. The following items are about activities you might do during a typical day. Does your health now limit you in these activities? Is so, how much?

PF01 a. Vigorous activities, such as running, lifting heavy objects, participating in strenuous sports

PF02 b. Moderate activities, such as moving a table, pushing a vacuum cleaner, bowling, or playing golf PF03 c. Lifting or carrying groceries
PF04 d. Climbing several flights of stairs
PF05 e. Climbing one flight of stairs
PF06 f. Bending, kneeling, or stooping
PF07 g. Walking more than a mile
PF08 h. Walking several blocks
PF09 i. Walking one block
PF10 j. Bathing or dressing yourself

4. During the past 4 weeks, have you had any of the following problems with your work or other regular daily activities as a result of your physical health?

RP1 a. Cut down on the amount of time you spent on work or other activities

RP2 b. Accomplished less than you would like

RP3 c. Were limited in the kind of work or other activities.

RP4 d. Had difficulty performing the work or other activities (for example, it took extra effort)

5 . During the past 4 weeks, have you had any of the following problems with your work or other regular daily activities as a result of any emotional problems (such as feeling depressed or anxious)

RE1 a. Cut down on the amount of time you spent on work or other activities

RE2 b. Accomplished less than you would like

RE3 c. Didn't do work or other activities as carefully as usual

SF1

6. During the past 4 weeks, to what extent has your physical health or emotional problems interfered with your normal social activities with family, trends, neighbors, or groups?

BP1 7. How much bodily pain have you had during the past 4 weeks?

BP2 8. During the past 4 weeks, how much did pain interfere with your normal work (including both work outside the home and housework)?

9. These questions are about how you feel and how things have been with you during the past 4 weeks. For each question, please give the one answer that comes closest to the way you have been feeling. How much of the time during the past 4 weeks

VT1 a. Did you fed full of pep?

$\mathrm{MH1}$ b. Have you been a very nervous per son?

$\mathrm{MH} 2$ c. Have you felt so down in the dumps that

nothing could cheer you up?

MH3 d. Have you felt calm and peaceful?

VT2 e. Did you have a lot of energy?

$\mathrm{MH} 4 \quad$ f. Have you felt downhearted and blue?

VT3 g. Did you fed worn out?

MH5 h. Have you been a happy person?

VT4 i. Did you feel tired?

SF2 10. During the past 4 weeks, how much of the time has your physical health or emotional problems interfered with your social activities (like visiting with friends, relatives, etc.)?

11. How TRUE or FALSE is each of the following statements for you?

GH2 a. I seem to get sick a little easier than other

people

GH3 b. I am as healthy as anybody I know

$\mathrm{GH} 4$ c. I expect my health to get worse

GH5 d. My health is excellent

SF-36 RESPONSE CHOICES

Excellent, Very good. Good, Fair, Poor

Much better now than one year ago, Somewhat better now than one year ago. About the same as one year ago, Somewhat worse now than one year ago, Much worse now than one year ago

Yes, limited a lot; Yes. limited a little; No, not limited at all 


\begin{abstract}
\& 5. Yes, No
Not at all, Slightly, Moderately, Quite a bit, Extremely

None. Very mild. Mild, Moderate, Severe, Very severe Not at all, A little bit. Moderately, Quite a bit, Extremely All of the time. Most of the time, A good bit of the time. Some of the time, A little of the time, None of the item All of the time. Most of the time. Some of the time, A little of the time, None of the time

Definitely true. Mostly true. Don't know. Mostly false. Definitely false
\end{abstract}

The study materials were statistically processed with parametric and non-parametric analysis methods. The accumulation, adjustment, systematization of initial information was carried out by Microsoft Office Excel 2016. Statistical analyses were performed by IBM SPSS Statistics v.23. Arithmetic mean values, standard deviations and coefficient of variation were calculated. The Mann-Whitney U-test was used to compare mean values in study groups.

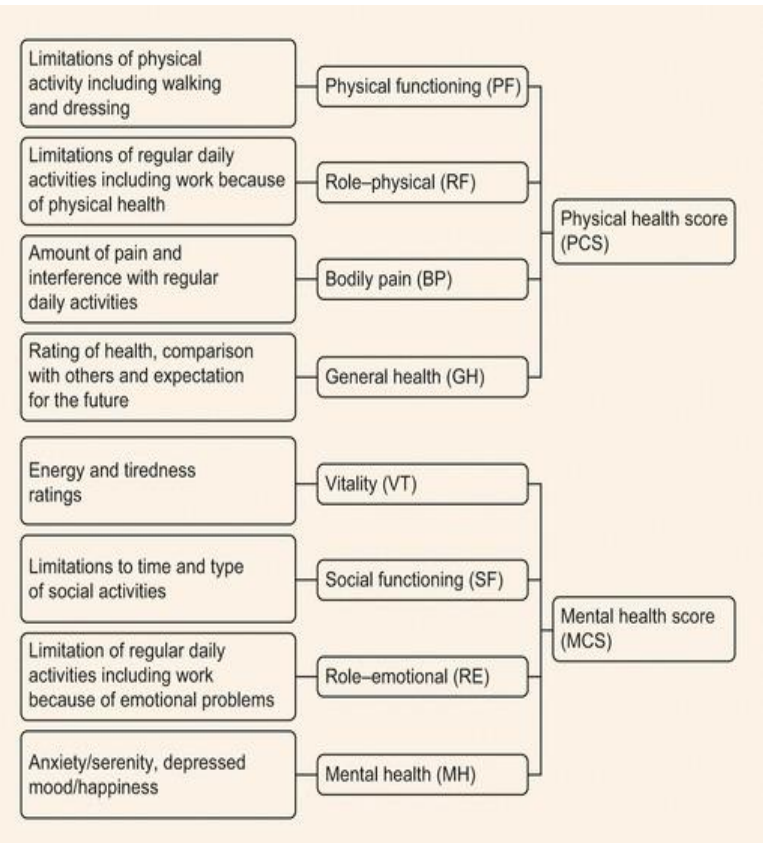

Figure 2. The structure of the Short Form 36 Health Survey (SF-36) instrument

\section{RESULTS AND DISCUSSION}

The study sample shows broad variability in the life quality of the surveyed population (Table 1).

Table 1. Generalized indicators of the life quality of patients with SCA1 and healthy representatives of the Yakut population

\begin{tabular}{|l|l|l|l|l|}
\hline life quality parameters & $\mathrm{n}$ & $\mathrm{M}$ & $\sigma$ & $\mathrm{U}$ \\
\hline Physical functioning & 24 & 70.8 & 29.1 & 41.1 \\
\hline $\begin{array}{l}\text { Role function due to } \\
\text { physical condition }\end{array}$ & 24 & 57.2 & 42.6 & 74.4 \\
\hline
\end{tabular}

\begin{tabular}{|l|c|c|c|c|}
\hline Pain intensity & 24 & 62.4 & 28.2 & 45.2 \\
\hline General health & 24 & 52.5 & 20.3 & 38.6 \\
\hline Life activity & 24 & 51.2 & 21.4 & 41.8 \\
\hline Social functioning & 24 & 64.0 & 27.4 & 42.7 \\
\hline Emotional Role Function & 24 & 50.0 & 41.7 & 83.4 \\
\hline Mental health & 24 & 62.0 & 17.0 & 27.4 \\
\hline $\begin{array}{l}\text { Physical component of } \\
\text { health }\end{array}$ & 24 & 60.7 & 25.2 & 41.5 \\
\hline $\begin{array}{l}\text { Psychological component } \\
\text { of health }\end{array}$ & 24 & 56.8 & 23.2 & 40.9 \\
\hline $\begin{array}{l}\text { Average Life Quality } \\
\text { Assessment }\end{array}$ & 24 & 58.7 & 23.0 & 39.1 \\
\hline
\end{tabular}

Note: $\mathrm{n}$ - number of observations; $\mathrm{M}$ - average value; $\sigma$ - standard deviation; $v$ - variation coefficient

The coefficient of variation, expressed in percentage, exceeds $30 \%$ threshold for all scales and components of the questionnaire, which indicates the heterogeneity of the indicators. The maximum level of variability is noted according to the scales "Role functioning due to emotional state" and "Role functioning due to physical state."

The life quality of SCA1patients is characterized by a significant decrease in indicators by the scales "Role functioning due to emotional state" and "Role functioning due to physical state," where the lowest average level of scores and their strong variation exceeding $100 \%$ (Table 2).

Table 2. Indicators of life quality of SCA1 patients

\begin{tabular}{|l|l|l|l|l|}
\hline Life quality parameters & $\mathrm{n}$ & $\mathrm{M}$ & $\sigma$ & $\mathrm{U}$ \\
\hline Physical functioning & 12 & 51.2 & 27.4 & 53.6 \\
\hline $\begin{array}{l}\text { Role function due to } \\
\text { physical condition }\end{array}$ & 12 & 33.3 & 35.8 & 107.6 \\
\hline Pain intensity & 12 & 48.5 & 26.1 & 53.8 \\
\hline General health & 12 & 45.0 & 22.2 & 49.3 \\
\hline Life activity & 12 & 50.4 & 16.3 & 32.3 \\
\hline Social functioning & 12 & 58.3 & 24.6 & 42.2 \\
\hline Emotional Role Function & 12 & 25.0 & 35.1 & 140.7 \\
\hline Mental health & 12 & 60.6 & 15.5 & 25.5 \\
\hline $\begin{array}{l}\text { Physical component of } \\
\text { health }\end{array}$ & 12 & 44.5 & 22.6 & 50.8 \\
\hline $\begin{array}{l}\text { Psychological component } \\
\text { of health }\end{array}$ & 12 & 48.6 & 19.8 & 40.8 \\
\hline $\begin{array}{l}\text { Average Life Quality } \\
\text { Assessment }\end{array}$ & 12 & 46.5 & 20.6 & 44.4 \\
\hline
\end{tabular}

Note: $\mathrm{n}$ - number of observations; $\mathrm{M}-$ average value; $\sigma$ standard deviation; $v$ - variation coefficient

Among healthy representatives of the Yakut population, relatively high quality levels were observed for all scales and components of the questionnaire (Table 3). At the same time, scales with a heterogeneous structure were noted (the coefficient of variation exceeds $30 \%$ ). This group of scales also includes "Role functioning due to physical condition" and "Role functioning due to emotional condition," a decrease in 
levels and heterogeneity of which was noted in SCA1 patients.

The average life quality levels for all types of examined scales and health components in SCA1patients and healthy people were compared to assess the structure of life quality of patients and identify its most sensitive components (Table 4).

Table 3. Indicators of life quality of healthy representatives of the Yakut population

\begin{tabular}{|l|l|l|l|l|}
\hline Life quality parameters & $\mathrm{n}$ & $\mathrm{M}$ & $\sigma$ & $\mathrm{U}$ \\
\hline Physical functioning & 12 & 90.4 & 13.5 & 14.9 \\
\hline $\begin{array}{l}\text { Role function due to } \\
\text { physical condition }\end{array}$ & 12 & 81.2 & 35.5 & 43.7 \\
\hline Pain intensity & 12 & 76.3 & 23.7 & 31.0 \\
\hline General health & 12 & 59.9 & 15.7 & 26.2 \\
\hline Life activity & 12 & 52.0 & 26.3 & 50.5 \\
\hline Social functioning & 12 & 69.7 & 29.8 & 42.8 \\
\hline Emotional Role Function & 12 & 75.0 & 32.1 & 42.9 \\
\hline Mental health & 12 & 63.3 & 18.9 & 29.9 \\
\hline $\begin{array}{l}\text { Physical component of } \\
\text { health }\end{array}$ & 12 & 76.9 & 15.6 & 20.3 \\
\hline $\begin{array}{l}\text { Psychological component } \\
\text { of health }\end{array}$ & 12 & 65.0 & 24.2 & 37.3 \\
\hline $\begin{array}{l}\text { Average Life Quality } \\
\text { Assessment }\end{array}$ & 12 & 71.0 & 18.8 & 26.5 \\
\hline
\end{tabular}

Note: $\mathrm{n}$ - number of observations; $\mathrm{M}$-average value; $\sigma-$ standard deviation; $v$ - variation coefficient

Table 4. Comparison of average estimates of life quality of SCA1 patients and healthy representatives of the Yakut population

\begin{tabular}{|l|l|l|l|}
\hline Life quality parameters & $\mathrm{U}$ & $\mathrm{z}$ & $\mathrm{p}$ \\
\hline Physical functioning & 16.0 & -3.20 & $\mathbf{0 . 0 0 0}$ \\
\hline $\begin{array}{l}\text { Role function due to } \\
\text { physical condition }\end{array}$ & 28.0 & -2.51 & $\mathbf{0 . 0 1 0}$ \\
\hline Pain intensity & 29.0 & -2.45 & $\mathbf{0 . 0 1 2}$ \\
\hline General health & 36.5 & -2.02 & $\mathbf{0 . 0 3 8}$ \\
\hline Life activity & 72.0 & 0.02 & 1.000 \\
\hline Social functioning & 54.0 & -1.01 & 0.318 \\
\hline Emotional Role Function & 21.5 & -2.88 & $\mathbf{0 . 0 0 2}$ \\
\hline Mental health & 61.5 & -0.57 & 0.551 \\
\hline $\begin{array}{l}\text { Physical component of } \\
\text { health }\end{array}$ & 19.5 & -3.00 & $\mathbf{0 . 0 0 1}$ \\
\hline $\begin{array}{l}\text { Psychological component } \\
\text { of health }\end{array}$ & 44.0 & -1.58 & 0.113 \\
\hline $\begin{array}{l}\text { Average Life Quality } \\
\text { Assessment }\end{array}$ & 27.0 & -2.56 & $\mathbf{0 . 0 0 8}$ \\
\hline
\end{tabular}

Note: U - Mann-Whitney test; $\mathrm{z}$ - standardized value of the criterion; $\mathrm{p}$ - two-way exact level of statistical significance
The research results established that a decrease in the life quality occurred for most indicators in the studied hereditary neurological pathology. This is evidenced by statistically significant differences in their averages compared to healthy individuals. At the same time, it seems interesting that patients maintain a level of life quality that does not differ from that of healthy persons due to the scales "Life activity," "Social functioning," "Mental health" and psychological health in general.

\section{CONCLUSION}

The pathology significantly reduces the life quality of patients according to the results of the Yakut population. First of all, the emotional state of the patients is deteriorating, which makes them spend more time doing everyday work, as well as reducing its volume. The next most important for patients is the deterioration of physical condition, which also greatly complicates the performance of daily work and household duties. On the other hand, even among healthy individuals, these parameters are characterized by wide variability with fairly high average scores.

The life quality feature of Yakut SCA1 patients can be considered a relatively good preservation of mental health, i.e., an optimistic attitude and positive emotions remain with a fairly low level of depressive and anxious experiences in general. Patients also maintain vital activity, normal level of communication and social contacts that are quite comparable to those of healthy persons. All this has a positive effect on the psychological component of the health of patients with SCA1.

Thus, established positive assessments of psychological health in SCA1 patients can contribute to the successful implementation of preventive measures and genetic screening in affected families. In addition, it is necessary to conduct psychological consultations and training improving the emotional state of patients.

The work was supported by the State Task of the Ministry of Science and Higher Education of the Russian Federation (project No. FSRG-2020-0014 "Genomics of the Arctic: epidemiology, heredity and pathology").

\section{REFERENCES}

[1] A.M. Duenas, R. Goold, P. Giunti, Brain 129 (2006) 1357-1370.

[2] P. Meera, S.M. Pulst, T.S. Otis, J. Physiol. 594 (2016) 4653-4660.

[3] D.R. Lynch, J. Farmer, J. Neuroophthalmol. 22 (2002) 297-304. 
[4] G. Coarelli, A. Brice, A. Durr, F1000Res. 7 (2018) 1781.

[5] S.H. Subramony, T. Ashizawa, in: R.A. Pagon et al. (Eds.), GeneReviews, Univ. of Wash., Seattle, WA, 2015.

[6] I. Paradisi, V. Ikonomu, S. Arias, J. Hum. Genet. 61 (2016) 215-222.

[7] F.A. Platonov, K. Tyryshkin, D.G. Tikhonov et al., Neurogenet. 17 (2016) 179-185.

[8] N. Buttner, D. Geschwind, J.C. Jen et al., Arch. Neurol. 55 (1998) 1353-1357.

[9] C.D. Stephen, J.D. Schmahmann, Cerebell. 18 (2019) 1130-1136.

[10] F.A. Klok, K.W. van Kralingen, A.P. van Dijk et al., Chest. 138 (2010) 1432-1440.

[11] A. Bunevicius, Health Qual. Life Outcomes 15 (2017) 92. 